\title{
UNA HISTORIA DE VIOLENCIA: EL PERÚ ENTRE LOS AÑOS 1980 A 1997
}

\author{
Miguel CAYUELA BERRUEZO \\ Universidad Ricardo Palma \\ miguel.cayuela@urp.edu.pe
}

\section{RESUMEN}

La población peruana fue la gran víctima durante la lucha entre las fuerzas armadas y los grupos terroristas en las décadas de 1980 y 1990. Este estudio se fundamenta desde la óptica de la memoria histórica. El artículo se centra principalmente en el enfrentamiento entre las Fuerzas Armadas y Sendero Luminoso. Durante la lucha, ambos bandos olvidaron los derechos humanos, todo por cumplir sus objetivos, el principal perdedor fue el Perú y toda su población. Perú entre 1980 y 1997 vivió una época de violencia sin control, que marcó para siempre a la nación peruana.

\section{PALABRAS CLAVE}

Memoria Histórica, paz, Perú, reconciliación, Sendero Luminoso, terrorismo, violencia

\section{A HISTORY OF VIOLENCE: PERU BETWEEN THE YEARS 1980 TO 1997}

\section{ABSTRACT}

The Peruvian population it was the victim during the confrontation between armed forces and the terrorists in the decades of 1980 and 1990. This study is based on optics of historical memory. The article focuses mainly on the confrontation between the Armed Forces and Sendero Luminoso. During the fight, both slides forgot human rights, all for fulfilling their objectives, the main loser was Perú and its entire population. Perú between 1980 and 1997 experienced an era of uncontrolled violence, which marked the Peruvian nation forever.

\section{KEY WORDS}

Historical Memory, peace, Perú, reconciliation, Sendero Luminoso, terrorism, violence.

Recibido: $25 / 03 / 2019$

Aprobado: 22/05/2019 


\section{Introducción}

a vuelta de la democracia al Perú, tras la dictadura militar del Gobierno Revolucionario de las Fuerzas Armadas del Perú (1968-1980), trajo la esperanza de recuperar la normalidad en todo el Perú. Pero, por desgracia la década de 1980 no fue fácil para todo el continente Latinoamericano, mientras que Argentina enfrentaba la dictadura militar de Videla (1976-1981), y en Chile la dictadura pinochetista ya estaba asentada, el Perú se enfrentaba ante el reto de volver a confiar en la democracia como el sistema político más idóneo, pero el Perú en su vuelta a la democracia tuvo que enfrentar desde el primer momento situaciones límite.

Fernando Belaúnde Terry volvía a ser presidente tras vencer en las elecciones de 1980, representando nuevamente al partido político Acción Popular (AP), los cinco años de Belaúnde Terry en el poder son recordados como el de la vuelta a la privatización en la economía peruana y el del inicio de las actividades terroristas por parte de Sendero Luminoso (1980) y del MRTA (1982), y por ende también el inicio de la lucha antiterrorista.

El siguiente presidente del Perú fue Alan García, representando a la Alianza Popular Revolucionaria Americana (APRA). El quinquenio de Alan García en el poder, fue un desastre económico de grandes proporciones, dejando al Perú en una situación económica muy delicada; en cuanto a la lucha antiterrorista, el gobierno tampoco estuvo a la altura de las circunstancias y Sendero Luminoso creció en poder, hasta finalmente llegaron y se asentaron en Lima hacia finales de la década de 1980, la que sería la batalla final para el grupo terrorista.

Con la llegada de la década de 1990, en el Cono Sur de América Latina, vieron nacer el llamado neopopulismo, liderado por Alberto Fujimori en el Perú y Carlos Menem en Argentina. En Chile, Augusto Pinochet dejaba de ser Presidente y volvía la democracia, nuevos aires democráticos y de justicia soplaban para el pueblo chileno. Desde 1990 y hasta el 2000, Alberto Fujimori gobernó el Perú cambiando para siempre la política peruana. Durante estos diez años se puso fin a la amenaza terrorista en gran parte del país, en primer lugar, con la captura del líder senderista, Abimael Guzmán el 12 de septiembre de 1992, y más tarde con la captura definitiva de Víctor Polay Campos en 1992 y la consecuente desaparición del MRTA en 1997, tras el éxito de la Operación Chavín de Huántar.

La paz que se instauró en el Perú no fue modélica, estuvo marcada por la violencia. Es importante dejar en claro este punto, ya que hoy en día todavía sigue estando presente en la selva del Perú la amenaza senderista, sobre todo en el Valle de los ríos Apurímac, Ene y Mantaro (VRAEM). Esto demuestra de que no fue una paz modélica, y que aún al día de hoy sigue estando presente el miedo ante un resurgimiento de Sendero Luminoso, más viendo grupos como el MOVADEF que intentan manipular a jóvenes peruanos desvirtuando la historia en favor de Abimael Guzmán y de Sendero Luminoso, están teniendo presencia en los últimos años en Lima. 


\section{Perú al borde de una guerra, la población es un enemigo más}

Durante la década de 1980 y hasta finales de la década de 1990, el Perú se enfrentó ante una situación de extrema gravedad. Sendero Luminoso desde el primer momento llamó a su enfrentamiento contra el Estado peruano como "la guerra popular"1 , mientras, todos los gobiernos peruanos confiaron en las Fuerzas Armadas del Perú para llevar a cabo el enfrentamiento y la política antiterrorista.

Mientras duró el enfrentamiento entre las Fuerzas Armadas y los terroristas, ambos bandos olvidaron los derechos humanos y la población civil fue la que sufrió las consecuencias. Fueron comunes las masacres llevadas a cabo por los dos bandos, si para matar a un terrorista había que masacrar a una comunidad entera, finalmente se terminaría por llevar a cabo tal acción. Hasta finales de la década de 1980, en el interior del Perú se vivió en una tensión constante, sobre todo en zonas como las de Ayacucho o Huancavelica, en donde los terroristas y las fuerzas armadas impusieron la ley marcial.

La población llegó a convertirse en un enemigo más para las Fuerzas Armadas y los terroristas. Sendero Luminoso utilizó a la población como un arma más contra las Fuerzas Armadas, de igual forma, Sendero Luminoso en las zonas que controlaban llevaban a cabo juicios populares, en donde sentenciaban a políticos, militares y personas civiles. La Fuerzas Armadas, también utilizaron a la población para poder llevar a cabo sus objetivos en la lucha antiterrorista, además atacaron poblaciones y comunidades en el interior del Perú, en los ataques murieron población civil y también terroristas, las bajas civiles las asumían como daños colaterales.

Fernando Belaúnde Terry y Alan García, delegaron toda la organización de la lucha antiterrorista en las Fuerzas Armadas, teniendo poco o ningún protagonismo el gobierno en la lucha antiterrorista. Quizás esa sea una de las explicaciones del porqué se obvió con tanta celeridad cualquier derecho humano en la lucha antiterrorista. En el caso de Alberto Fujimori es distinto, ya que el gobierno si tuvo presencia directa en la lucha antiterrorista gracias a la figura de Vladimiro Montesinos como director del SIN. ${ }^{2}$

La década que duró el mandato de Alberto Fujimori como presidente del Perú, estuvo siempre marcada por la vulneración de los derechos humanos. Los activistas por los derechos humanos empezaron a manifestarse a partir de la segunda mitad de la década de 1990 contra el gobierno de Alberto Fujimori. Amnistía Internacional puso el foco en Perú, y como se estaba llevando a cabo la lucha antiterrorista, como lo bien lo deja en claro Hugo Relva (2009):

La sala declaró que las víctimas (entre las que se encontraba un niño de ocho años) no eran terroristas, desmintiendo la injuriosa afirmación de que las ejecuciones del Grupo

1 Abimael Guzmán y toda la cúpula senderista justificó el enfrentamiento contra el Estado peruano, argumentando que estaban luchando por liberar al pueblo peruano de un sistema de gobierno injusto y que no miraba por la población más necesitada. A pesar de que Sendero Luminoso se justificaba porque según ellos luchaban por el pueblo, no dudaron nunca en atacar a la población peruana si la "guerra popular" así lo requería.

2 El Servicio de Inteligencia Nacional del Perú, durante el gobierno fujimorista tuvo una importancia capital en la lucha antiterrorista. Dirigido por Vladimiro Montesinos capitaneó los principales episodios durante la lucha antiterrorista de la década de 1990, como el de Barrios Altos o el de La Cantuta. 
Colina, cuya supervisión ejercía Fujimori, habían sido la respuesta a actos de violencia inusitada cometidos por Sendero Luminoso. Esta circunstancia tiene un valor simbólico inmenso para los familiares de las víctimas, contra quienes pesaba falsamente un injusto estigma que siempre rechazaron.

Relva se refiere a las víctimas de la masacre de Barrios Altos, uno de los episodios que más se recuerdan en la lucha antiterrorista ${ }^{3}$. Según los datos ofrecidos por la Comisión de la Verdad y la Reconciliación (CVR), durante la contienda hubo un total de 69.280 víctimas civiles (CVR, 2003, p. 13). El Ministerio de Justicia y Derechos Humanos (MINJUS) del gobierno peruano, también hizo un registro sobre las víctimas totales, lo llamaron Registro Único de Víctimas (RUV), para el gobierno peruano hubo un número de víctimas mucho mayor, incrementando el número de víctimas a más de 249.000 personas. ${ }^{4}$

A continuación, pondré los datos que ha ofrecido el Lugar de la Memoria, la Tolerancia y la inclusión social del Ministerios de Cultura del Perú (LUM), no están todas las víctimas, pero podemos hacernos una idea de la cantidad de víctimas que hubo durante el enfrentamiento:

Datos facilitados por la CVR: 2.218 desparecidos, 5.684 detenidos, 1.390 detenidos y desaparecidos, 908 lesionados o heridos, 2 reclutados de forma forzosa, 10.735 asesinados y ejecutados extrajudicialmente, 171 muertos en atentados, 533 muertos en enfrentamientos, 504 reclutados, 3.345 secuestrados, 5.811 torturados, 425 violadas sexualmente. ${ }^{5}$

Datos facilitados por el RUV: 8.840 desapariciones forzosas, 66.083 desplazamientos forzosos, 17.209 detenciones arbitrarias, 23.910 fallecidos, 36 indebidamente requisitoriado, 47 indocumentados, 644 menores integrantes del CAD, 1.501 encarcelados siendo inocentes, 2.111 reclutados forzosamente, 13.881 secuestrados, 48.003 torturados, 1.123 víctimas con alguna discapacidad, 12.483 víctimas heridas o lesionadas, 4.471 violadas sexualmente, 1.475 violentadas sexualmente. ${ }^{7}$

\section{LAS MASACRES LLEVADAS A CABO EN EL PERÚ DURANTE LA CONTIENDA, LA POBLACIÓN ES LA PRINCIPAL VÍCTIMA}

Sendero Luminoso es el grupo terrorista más sanguinario de la historia del Perú, con un 54\% de las muertes totales durante el conflicto entre el Estado peruano y los grupos terroristas (CVR, 2003, p. 15). La población más afectada fue la del interior, Ayacucho fue la provincia más afectada con el $50 \%$ de los asesinatos llevados a cabo por Sendero Luminoso a nivel nacional (CVR, 2003, p. 16).

3 El episodio de Barrios Altos es considerado como un símbolo en cuanto a la violación de los derechos humanos, entre las víctimas se encontraba un niño de 8 años.

4 Para más información puede visitar el portal del RUV: http://www.ruv.gob.pe/

5 Todos los datos están en el siguiente enlace: http://lum.cultura.pe/cdi/busqueda.

6 Menores de edad que integraron un Comité de Autodefensa, obligados a luchar siendo menores de edad (18), o participar directa o indirectamente en actividades del CAD.

7 Para más información de los datos ofrecidos del RUV, también puede visitar la base de datos del LUM, en el siguiente enlace: http://lum.cultura.pe/cdi/busqueda. 
Una de las masacres más significativas llevada a cabo por Sendero Luminoso fue la de Lucanamarca, que sucedió en 1983, en la provincia de Huanca Sancos (Ayacucho), la masacre dejó el balance de 69 personas muertas, las víctimas fueron hombres, niños, mujeres y ancianos (CVR, 2003, p. 52). Se estima que durante la "guerra popular", según la CVR, Sendero Luminoso fue autor de 215 masacres (CVR, 2003, p. 21), aunque este número podría aumentar, ya que según la Fiscal que logró condenar a Abimael Guzmán, Luz lbáñez, todavía queda mucho trabajo por hacer en la investigación de las masacres llevadas a cabo por Sendero Luminoso. El Perú vivió muchas masacres como la ocurrida en Lucanamarca, Luz Ibáñez desde 2016 está estudiando 10 masacres más que posiblemente llevó a cabo Sendero Luminoso; en septiembre de 2016 afirmaba para El Comercio que: "Masacres más grandes de Sendero recién se están descubriendo".8

En la "guerra popular" Sendero Luminoso atacó a objetivos políticos, militares, dirigentes comunales, campesinos prósperos y ronderos. Todos estos asesinatos, desde la cúpula de Sendero Luminoso, lo justificaban explicando que estas personas eran enemigas contra el progreso senderista, los consideraban traidores a la nueva patria que Sendero Luminoso crearía para el Perú.

Atentados como el ocurrido el 16 de julio de 1992 en Lima, en el distrito de Miraflores, fue común en el accionar de Sendero Luminoso. En el atentado murieron 18 personas y 200 personas quedaron heridas, además de atacar cuatro comisarías. Los diarios como la República titularon la portada del día siguiente: "Miraflores, jun infierno!" (La República, 1992, p. 1), el diario Ojo por su parte titulaba el reportaje del atentado como: "Horror, destrucción y muerte en centro de Miraflores" (Ojo, 1992, p.3).

Las Fuerzas Armadas actuaron de forma eficaz y violenta contra los terroristas. Cuando Alan García sucedió a Fernando Belaúnde Terry en el poder, García prometió preservar ante todo los derechos humanos en la lucha antiterrorista. Pero, el 14 de agosto de 1985 ocurrió la masacre de Accomarca en Ayacucho. El ejército entró en el poblado bajo el pretexto de que en la zona había una supuesta base de formación terrorista de Sendero Luminoso, la incursión de las Fuerzas Armadas según la CVR dejaron un saldo de 62 víctimas mortales (CVR, 2003, p. 155), 23 de ellos niños, aunque la verdad que hasta el día de hoy sigue habiendo bastante polémica, ya que los familiares datan los asesinatos en 71 personas 9 . Alan García decidió destituir al comandante conjunto de las Fuerzas Armadas en la zona de Ayacucho, Telmo Hurtado ${ }^{10}$.

Como respuesta, los militares se negaron a actuar en el sur andino por más de nueve meses. Estos nueve meses permitieron a Sendero Luminoso retomar y expandir su influencia en el sur del Perú. Al ver el avance de Sendero Luminoso por prácticamente todo el territorio peruano, Alan García reculó con las Fuerzas Armadas y los dejó

8 Para más información puede ver la noticia en el siguiente enlace: https://elcomercio.pe/politica/justicia/ masacres-grandes-sendero-recien-descubriendo-399032.

9 Para más información puede acceder a la noticia donde se hablaba de que el número de asesinados era mayor en el siguiente enlace: https://www.bbc.com/mundo/noticias-america-latina-37254469.

10 Conocido como el "Monstruo de Accomarca" y el "Carnicero de los Andes", en 1993 fue condenado a 6 años de cárcel por la masacre de Accomarca. Con el decreto Ley de Amnistía promulgada en 1995 por Alberto Fujimori su sentencia quedó anulada. En el año 2011 cuando vuelve a ser juzgado. El juicio dictaminó 25 años de prisión y el pago de 14 millones de dólares como reparación civil. 
trabajar de nuevo libremente. Los comandantes volvían a tener todo el poder de decisión a la hora de elaborar las actuaciones militares y como debían llevarse a cabo.

Al poco tiempo de regresar los militares al frente de la lucha antiterrorista, ocurrió la "matanza en los penales del Perú" en 1986, los hechos sucedieron en los penales de San Juan de Lurigancho, El Frontón y en la cárcel de mujeres de Santa Bárbara. En estas cárceles cumplían condena miembros de Sendero Luminoso; los presos se amotinaron apresando a los guardias de las cárceles y a tres periodistas. La respuesta por parte de las Fuerzas Armadas fue contundente, la actuación dejó un balance de 133 víctimas mortales. ${ }^{11}$ Hasta el día de hoy la "matanza de los penales del Perú" genera bastante controversia, debido a que no se tiene claro si los amotinados fueron ejecutados o perdieron la vida durante la incursión de las Fuerzas Armadas en los penales.

A partir de 1986, las vulneraciones de los derechos humanos aumentaron considerablemente, se restringió todo acceso civil a las zonas declaradas de emergencia, incluso expulsaron a la Cruz Roja de Ayacucho en 1988. El control militar en estas zonas era total. El 14 de mayo de 1988 ocurrió la Masacre de Cayara, en el que un grupo de soldados mataron a 39 campesinos de la comunidad de Cayara (Pariona, 2017), las Fuerzas Armadas justificaron esta intervención como respuesta a una emboscada que llevó a cabo Sendero Luminoso a una patrulla del ejército el día anterior en la zona.

En el gobierno de Alberto Fujimori (1990-2000), en materia de lucha antiterrorista se hicieron célebres grupos como el de Colina, el cual estaba integrado por militares y miembros de la Policía nacional. Este grupo fue el responsable de la masacre de Barrios Altos en Lima, donde fueron asesinadas 15 personas en noviembre de 1991 (CVR, 2003, p. 475), y de la masacre de La Cantuta, el 18 de julio de 1992, en la Universidad Nacional de Educación Enrique Guzmán y Valle, que ejecutaron a nueve estudiantes y un profesor, bajo la acusación de pertenecer a Sendero Luminoso (CVR, 2003, p. 236).

La violación de derechos humanos fue habitual en la forma de proceder por parte de las Fuerzas Armadas durante la década que estuvo Alberto Fujimori al poder. Era común que, cuando detenían a algún miembro o una persona sospechosa de pertenecer a algún grupo terrorista, fuesen torturados privándoles de uno o más de sus sentidos, como la vista, los oídos o el habla durante un tiempo prolongado, todo ello para que el interrogado se derribara psicológicamente y acabase confesando. Durante el interrogatorio los detenidos estaban maniatados o inmovilizados. Además, les daban palizas, les insultaban, le amenazaban al interrogado de que si no cooperaba, sus familiares sufrirían daños.

En los interrogatorios pasaron todo tipo de personas durante la década fujimorista, es así como en ocasiones eran detenidos e interrogados personas que su relación con Sendero Luminoso o el MRTA podría ser el de simplemente tener un parentesco familiar con los terroristas. En otros casos, el detenido no era terrorista, ni tenía

11 Véase el siguiente enlace para tener más información del caso: https://peru21.pe/politica/caso-fronton-acusacion-fiscal-incluye-33-marinos-99563. 
parentesco alguno con los terroristas. Incluso se llegó a torturar a periodistas y personas que eran contrarias a Alberto Fujimori.

El 22 de abril de 1997 terminó la lucha antiterrorista con la Operación Chavín de Huántar. El 17 de diciembre de 1996, el MRTA tomó la embajada de Japón en el Perú, haciendo prisioneros en torno a 600 personas que acudieron para celebrar el aniversario del natalicio del Emperador japonés Akihito (CVR, 2003, p. 720), más los trabajadores de la Embajada, todas las mujeres fueron puestas en libertad durante la primera noche, entre los prisioneros estaban personalidades como Alejandro Toledo, Javier Diez Canseco o el historiador peruano Fernando Rosas Moscoso. Previa liberación de 38 prisioneros, las Fuerzas Armadas tomaron la embajada y mataron a los 14 miembros del MRTA que estaban dentro del recinto, Sandoval (líder de la operación) perdió la vida durante la toma de la embajada, pero el resultado fue un éxito para Alberto Fujimori, que a pesar de haber perdido dos militares de los 140 que iniciaron la operación, y de perder un rehén en el rescate, salvaron a los 71 rehenes restantes (Álvarez, 2015, pp. 57-60).

\section{LA VIOLENCIA SOBRE LAS MUJERES PERUANAS}

Durante el conflicto armado las mujeres peruanas también fueron violentadas, la mayoría de casos fueron de carácter sexual. Según el informe final de la CVR, las mujeres representan el $20 \%$ de desapariciones y muertes durante el conflicto armado entre el gobierno peruano y los grupos terroristas (CVR, 2003, p. 66).

La violencia sufrida por las mujeres, también fue de carácter vejatorio, como tocamientos, amenazas de violación, desnudos forzados, introducción de objetos, abortos forzados, uniones forzadas y hasta esclavitud sexual (Alvites y Alvites, 2007, p.131). Este tipo de violencia fue sobre todo común en la zona del interior del Perú, en la sierra y la selva peruana.

Según la CVR, la violencia sobre las mujeres fue llevada a cabo en gran medida por las Fuerzas Armadas (sobre todo miembros del Ejército, de la Marina de Guerra y en último lugar las fuerzas policiales), pero también los miembros de Sendero Luminoso llevaron a cabo actos violentos sobre las mujeres peruanas (CVR, 2003, p. 263).

En total fueron 7.426 mujeres las que fueron víctimas de desapariciones forzadas, detenidas, torturadas y ejecutadas extraoficialmente (CVR, 2003, p. 275). El origen de las mujeres maltratadas en el Perú durante la lucha antiterrorista, estuvo principalmente enfocada en las mujeres quechua hablantes $(75 \%)$, en las zonas rurales (83\%), en menor medida fueron violentadas mujeres campesinas (36\%) y con un $30 \%$ las amas de casa también sufrieron abusos sexuales, o violentadas de alguna forma (CVR, 2003, p. 276).

Como en el caso de las Fuerzas Armadas, los integrantes de Sendero Luminoso, durante sus incursiones armadas en pueblos de los Andes y del Amazonas, llevaron 
a cabo violaciones, también violaron a mujeres durante las llamadas "retiradas"12, donde mantenían en régimen de servidumbre a un número sin determinar de personas.

Durante las incursiones de Sendero Luminoso, violaron principalmente a niñas y mujeres, además de utilizar la violación como un método de reclutamiento para la causa senderista. Primero, violaban a la mujer y segundo, la mentalizaban o las obligaban a ser reclutadas. También hubo casos de secuestros de mujeres, las cuales eran obligadas a acompañar a los senderistas en sus viajes, principalmente eran mujeres jóvenes, además, era común que se quedasen embarazadas durante el secuestro, en muchos casos producto de una violación.

En los campamentos de Sendero Luminoso llegó a haber servidumbre sexual, en donde era común, que las mujeres secuestradas fuesen esclavas sexuales de los comandos senderistas. El destino de las mujeres, en los campamentos senderistas era incierto, a veces ocurría, que un alto cargo senderista se encaprichase de una mujer en cuestión, se la llevase con él, se cansase después de un cierto tiempo, y la mujer acabase siendo asesinada, en otros casos también podían ser liberadas, aunque este caso último era el menos común.

También llegaron a darse casos de pederastia en los campamentos senderistas, en donde, en ocasiones, sobre todo en fiestas, terminaron abusando sexualmente de niñas.

\section{CONCLUSIONES}

Como se ha podido constatar a lo largo del artículo, la paz que se implantó en el Perú llegó a través de la violencia, es por ello que al día de hoy siguen heridas abiertas en cierto sector de la población peruana. No siempre la política antiterrorista debe estar exclusivamente en manos de las Fuerzas Armadas de un país. También se debe intentar luchar contra el adversario mediante el diálogo, el consenso, una estrategia conjunta entre todos los medios que puede proporcionar un Estado democrático.

La CVR elaborada en 2003, fue un gran avance en la búsqueda de la reconciliación nacional, seguida por la creación del archivo y museo histórico del LUM y la Ley $30470^{13}$. Aun así, queda mucho camino por realizar, pero solo por el camino de la reconciliación y el perdón es posible acabar con la amenaza terrorista que queda en la selva peruana y los brotes senderistas que comienzan a verse por Lima, representados por el MOVADEF. Solo así se podrá acabar con movimientos como el MOVADEF, que solo busca dividir y sobre todo confundir a un núcleo de población peruana (jóvenes) que no vivieron lo que ocurrió entre los años 1980 a 1997 en el

12 Las "retiradas" eran épocas que utilizaban los comandos senderistas para descansar, poder rearmarse y reclutar nuevos miembros.

13 Ley aprobada por el gobierno del Perú bajo el gobierno de Ollanta Humala en 2016, es la Ley de búsqueda de personas desaparecidas durante el periodo de violencia 1980-2000, para más información pueden visitar el siguiente enlace: https:/www.acnur.org/fileadmin/Documentos/BDL/2016/10698.pdf?file=fileadmin/ Documentos/BDL/2016/10698. 
Perú. Movimientos como los del MOVADEF deben ser combatidos con la verdad, con la paz.

El Perú debe encaminarse hacia la reconciliación nacional, ya lo está intentando desde el medio legal con la Ley 30470, para poder acceder y cerrar una paz, no ya perfecta, pero al menos acercase a una reconciliación con todo el pueblo peruano. En donde, todas las víctimas de esta lucha sean reconocidas.

En los últimos años están apareciendo una serie de investigadores peruanos y extranjeros, que están comenzando a tratar lo ocurrido en el Perú desde una perspectiva más social. Quizás movidos más por la memoria, Carlos Iván Degregori, ya fallecido, fue el investigador peruano más notable a la hora de tratar el conflicto, además de convertirse en el maestro de las nuevas generaciones peruanas que abordan el enfrentamiento entre las Fuerzas Armadas y los terroristas.

Hay que educar a la población peruana en los valores de la democracia, por ello es de capital importancia que la población peruana sepa lo que ocurrió. Hay que evitar que vuelva a suceder algo similar en el Perú, y sobre todo educar y concienciar a la población peruana en una cultura donde se respeten todos los derechos humanos.

Es por ello, que es tan importante la memoria histórica, toda sociedad debe recordar la historia de su pueblo sin alteraciones. Las víctimas de ambas partes merecen el reconocimiento como tal. La memoria histórica debe servir sobre todo para que el pueblo peruano no olvide una época en la que el terror se adueñó del Perú.

El Estado peruano durante la contienda y la lucha antiterrorista, como hemos visto, dejó de lado los derechos humanos, actuaron con la mayor dureza posible contra el horror que estaban creando Sendero Luminoso y el MRTA en el Perú. Es por ello tan importante mantener viva la memoria de lo ocurrido entre 1980 y 1997 . Como bien reza el nombre del artículo, lo que ocurrió en el Perú fue una historia de violencia, que jamás debe repetirse.

Este artículo es un pequeño grano de arena para la lucha por la democracia y por la paz en el Perú, ya que solo se conseguirá la paz cuando contemos la historia de todos, solo así se reforzará nuestra democracia y la paz, como bien lo dejan en claro Fernando Martínez y Miguel Gómez (2014):

La recuperación de la Memoria Histórica ha de convertirse, en suma, en la construcción de un relato que, nutrido del discurso histórico más riguroso posible, explique nuestro pasado en una clave de defensa de los valores y de las instituciones democráticas, que fomente el ejercicio de la virtud cívica y contribuya a consolidar y profundizar nuestro régimen democrático.

\section{BIBLIOGRAFÍA}

Ávarez, A. (2015). La toma de rehenes como acto terrorista internacional. Análisis de la operación de rescate $<<$ Chavín de Huantar $>>$. Revista de relaciones internacionales, estrategia y seguridad, vol.10, n², pp. 43-68. 
Alvites, E. C. y Alvites, L. M. (junio de 2007). Mujer y violencia política. Notas sobre el impacto del conflicto armado interno peruano. Feminismo/s, 9, pp. 121-137.

Aragón, L. (agosto de 2007). La violencia contra la Mujer Ayacuchana durante el conflicto armado interno del Perú 1980-2000. Psicología sin Fronteras, vol. 2, nº 1 у 2 , pp. 56-57.

Azevedo, V. R. (2015). Memorias oficiales, memorias silenciadas en Ocros (Ayacucho, Perú). Reflexiones a partir de la conmemoración de una masacre senderista. Anthropologica, año XXXIII, nº 34, pp. 147-164.

Benavides, J. E. (2005). Violencia política y narrativa en el Perú de los años ochenta. Quórum. Revista de pensamiento iberoamericano, núm. 11, pp. 153-162

Bonilla, H. (2003), "Sendero Luminoso en la encrucijada política del Perú". Nómadas, núm. 19, pp. 58-65.

Burt, J. (2011). Violencia y autoritarismo en el Perú. Bajo la sombra de Sendero y la dictadura de Fujimori, Lima: IEP.

Canchari, R. Y. (2016). Mujer, memoria y conflicto armado en el Perú: Hacia una perspectiva de responsabilidad para proteger a la luz del derecho internacional de los derechos humanos", en V.V.A.A., Mujeres e investigación. Aportaciones interdisciplinares, Sevilla: pp. 95-107.

Cóndor, N. y P, N. E. (2015). Desaparecidos en la penumbra del atardecer: disputas privadas, memoria y conflicto armado en San Miguel (Ayacucho). Anthropologica, año XXXIII, n³ 34, pp. 63-88.

Cotler, J. y Grompone, R. (2000). El fujimorismo, ascenso y caída de un régimen autoritario, Lima: IEP.

Daniela, F. (2015). El Perú y sus múltiples Sendero Luminoso, Relaciones Internacionales, n49, pp. 51-75.

Degregori, C. I. (ed.) (2003). Jamás tan cerca arremetió lo lejos. Memoria y violencia política en el Perú, Lima: IEP.

Degregori, C. I., Coronel, J., Del Pino, P. y Starn, O. (1996). Las rondas campesinas y la derrota de Sendero Luminoso, Lima: IEP.

Del Pino, P. y Yezer, C. (2013). Las formas del recuerdo: etnografía de la violencia política en el Perú, Lima: IEP.

Gurmendi, A. (2013). Lucha contrasubversiva en el Perú: ¿Conflicto armado o delincuencia terrorista? Themis, Revista de derecho, 63, pp. 109-129.

Malvaceda, E. (2010). Ñakari - Formas culturales de sufrimiento tras la violencia política en el Perú, Revista IIPSI, vol. 13, n², pp. 129-138. 
Murakami, Y. (2013). Perú en la era del chino: la política no institucionalizada y el pueblo en busca de un salvador, Lima: IEP.

Orduña, E. L. (2012/4). Derechos humanos y crímenes de lesa humanidad en América Latina, Cuadernos Americanos, 142, pp. 153-168.

Relva, H. (agosto de 2009). El caso Fujimori, un hito histórico, Amnistía Internacional, n०98, pp. 18-19.

Rénique, J. L. (2003). La voluntad encarcelada: Las luminosas "trincheras de combate" de Sendero Luminoso del Perú, Lima: IEP.

Stern, J. S. (ed.) (1999). Los senderos insólitos del Perú. Guerra y sociedad, 1980-1995, Lima: IEP.

Theidon, K. (2004). Entre prójimos, el conflicto armado interno y la política de la reconciliación en el Perú, Lima: IEP.

Thorndike, G. (1983). Uchuraccay: testimonio de una masacre, Lima, Guillermo Thorndike editor EIRL.

Zeledón, G. (octubre de 1995). "Contradicciones en la sociedad peruana. El caso de Sendero Luminoso", Reflexiones, (39), pp. 19-33.

\section{FUENTES}

ANFASEP (2007). ¿ ¿Hasta cuando tu silencio? Testimonio de dolor y coraje, Lima.

Archivo del museo del Lugar de la Memoria la Tolerancia y la Inclusión Social (LUM).

Archivo del Registro Único de Víctimas (RUV) del Ministerio de Justicia y Derechos Humanos del Perú.

CVR (Comisión de la Verdad y la Reconciliación), (2003). Informe final, Tomo II. Lima: CVR. (2003). Informe final, Tomo VI. Lima: CVR. (2003). Informe final, Tomo VII. Lima: CVR. (2003). Informe final, Tomo VIII. Lima: CVR.

Ley 30470 de Búsqueda de personas desaparecidas durante el periodo de violencia 1980-2000, 22 de junio de 2016.

\section{REFERENCIAS PERIODÍSTICAS}

El diario Marka, 1 de noviembre de 1980. 
El diario Marka, 19 de abril de 1982.

El diario, 7 de enero de 1987, año VIII, no 292.

La República, 13 de septiembre de 1992.

La República, 17 de julio de 1992.

Ojo, 13 de septiembre de 1992.

Ojo, 17 de julio de 1992.

Página Libre, Lunes 09 de abril de 1990.

Pariona, T. (18 de julio de 2017), Cayara, 29 años después, La República.

\section{REFERENCIAS WEB}

http://lum.cultura.pe/cdi/busqueda/afectacion?a_ta=All\&a_anio=\&a_mes=All\&a_ dia $=\& a \_u b i c=A l l \&=B u s c a r 2$ de enero de 2017.

http://lum.cultura.pe/cdi/busqueda4 de enero de 2017.

http://www.ruv.gob.pe/.

https://elcomercio.pe/politica/justicia/masacres-grandes-sendero-reciendescubriendo-399032.

https://peru21.pe/politica/caso-fronton-acusacion-fiscal-incluye-33marinos-99563.

https://www.bbc.com/mundo/noticias-america-latina-37254469. 